\title{
Using patient-collected clinical samples and sera to detect and quantify the severe acute respiratory syndrome coronavirus (SARS-CoV)
}

\author{
Zhongping $\mathrm{He}^{1,2}$, Hui Zhuang3, Chunhui Zhao², Qingming Dong1, \\ Guoai Peng ${ }^{1}$ and Dominic E Dwyer*4
}

\begin{abstract}
Address: ${ }^{1}$ Beijing Ditan Hospital, Beijing 100011, People's Republic of China, ${ }^{2}$ Capital University of Medical Sciences Affiliated Beijing YouAn Hospital, Beijing 100054, People's Republic of China, ${ }^{3}$ Department of Microbiology, Peking University Health Science Center, Beijing 100083, People's Republic of China and ${ }^{4}$ Centre for Infectious Diseases and Microbiology Laboratory Services, Institute of Clinical Pathology and Medical Research, Westmead Hospital, Westmead NSW 2145, Australia

Email: Zhongping He - zhongpinghe@yahoo.com; Hui Zhuang - zhangbmu@126.com; Chunhui Zhao - yabgc9329@sina.com; Qingming Dong -dqm3@sina.com; Guoai Peng - pengguoai@yahoo.com.cn; Dominic E Dwyer* - dominic_dwyer@wmi.usyd.edu.au

* Corresponding author
\end{abstract}

Published: 27 March 2007

Virology Journal 2007, 4:32 doi:10.1186/1743-422X-4-32

This article is available from: http://www.virologyj.com/content/4/I/32

(C) 2007 He et al; licensee BioMed Central Ltd.

This is an Open Access article distributed under the terms of the Creative Commons Attribution License (http://creativecommons.org/licenses/by/2.0), which permits unrestricted use, distribution, and reproduction in any medium, provided the original work is properly cited.
Received: 13 February 2006

Accepted: 27 March 2007

\begin{abstract}
Background: Severe acute respiratory syndrome (SARS) caused a large outbreak of pneumonia in Beijing, China, in 2003. Reverse transcriptase polymerase chain reaction (RT-PCR) was used to detect and quantify SARS-CoV in 934 sera and self-collected throat washes and fecal samples from 27I patients with laboratory-confirmed SARS managed at a single institution.

Results: SARS-CoV detection rates in sera were highest in the first 9 days of illness, whereas detection was highest in throat washes 5-14 days after onset of symptoms. The highest SARS-CoV RT-PCR rates $(70.4-86.3 \%)$ and viral loads $\left(\log _{10} 4.5-6.1\right)$ were seen in fecal samples collected 24 weeks after the onset of clinical illness. Fecal samples were frequently SARS-CoV RT-PCR positive beyond 40 days, and occasional sera still had SARS-CoV detected after 3 weeks of illness.

Conclusion: In the context of an extensive outbreak with major pressure on hospital resources, patient self-collected samples are an alternative to nasopharyngeal aspirates for laboratory confirmation of SARS-CoV infection.
\end{abstract}

\section{Background}

Severe acute respiratory syndrome (SARS) emerged in late 2002, with more than 8096 cases reported by April 21 2004 by the World Health Organization, mostly in China (5327), Taiwan, Hong Kong SAR, Singapore and Canada. There were 774 deaths and a mortality of $9.6 \%$ [1]. The largest outbreak was in Beijing, with over 2,521 cases [2]. The SARS-associated coronavirus (SARS-CoV) was identified as the causal agent following its isolation and detec- tion by electron microscopy and reverse transcriptase polymerase chain reaction (RT-PCR) from a range of clinical specimens. Serological evidence of infection has been found in most patients fitting the clinical definition of SARS [3-6]. The clinical, radiological, and laboratory findings of SARS from Beijing and elsewhere have been described previously $[2,5,7-12]$. 
The aim of this study was to detect and quantify SARSCoV using RT-PCR in sera and throat washes and stools self-collected by 271 patients with laboratory confirmed SARS managed at a single institution. These samples were collected during the extreme pressure of the Beijing SARS outbreak in the context of healthcare worker concern about the safety of collecting nsaopharyngeal aspirates (NPAs) from ill patients.

\section{Results}

Between March 26-May 31 2003, 304 patients fitting the case definition of probable SARS were hospitalized. Of these, 271 were laboratory confirmed following the detection of SARS-CoV-specific IgM and/or IgG antibody by immunofluorescence [6] and/or by the detection of SARSCoV RNA by RT-PCR.

The mean age of the cohort was $36 \pm 16$ years. There were $92(33.9 \%)$ healthcare workers who acquired SARS, including 51 nurses, 30 physicians, 5 logistics staff, 3 pharmacists and 2 laboratory technicians (one of whom was believed to be infected after handling sputum and stool samples from SARS patients in a diagnostic laboratory). A total of 112 people were infected following exposure to SARS patients in the hospital setting, either as healthcare workers, patients or visitors, and another 62 cases were household contacts of known SARS cases. Common clinical features on admission included fever (100\%), subjective shortness of breath (57\%), nonproductive cough $(55 \%)$, malaise $(52 \%)$, myalgia $(38 \%)$, headache (30\%), dyspnea (21\%), chills (17\%), diarrhea (11\%) and sore throat (6\%). The mortality rate was $9.2 \%$ (25/271) amongst laboratory-confirmed cases.

Sera, throat washes and stool samples were tested for SARS-CoV RNA by RT-PCR. A total of 614 sera (ranging from 1-7 per patient) were collected 1-78 days after the onset of illness from 271 cases. Overall, 31.3\% (192/614) of sera had detectable amounts of SARS-CoV RNA detected, with viral loads ranging from $10^{1}-10^{3}$ copies $/ \mathrm{ml}$ serum (Table 1). Sera collected within 9 days of disease onset were more likely to be RT-PCR positive (54\%) than later in the disease course, although SARS-CoV RNA was still occasionally detected in sera out to 24 days of illness.

A single throat wash was self-collected by 96 patients 1 to 35 days after the onset of disease. A total of 50 (52.1\%) had SARS-CoV RNA detected by RT-PCR (Table 2), with viral loads ranging from $10^{1}-10^{5}$ copies $/ \mathrm{ml}$ wash fluid. The highest detection rate was $61 \%$ in throat washes collected between days 5 and 14 .

Of 224 stool samples self-collected by 188 patients (1-2 samples each), 127 (56.7\%) had SARS-CoV RNA detected by RT-PCR (Table 3 ). Stool samples were not collected in the first 10 days of illness, but high rates of SARS-CoV RNA detection $(44 / 51,86.3 \%)$ were seen in stools collected between 10 and 19 days after onset. Viral loads in stool were as high as $10^{10}$ copies/g feces from day 10 . Fecal samples collected 40 days or more after onset of disease contained SARS-CoV RNA in 29.8\% (17/57) of samples, with a mean load of 7000 copies/g feces. The fecal load of SARS-CoV was at least between 2 and 3 logs higher than in throat washes or sera at comparable time points.

\section{Discussion}

The clinical features of this cohort of 271 patients managed at a single institution were similar to those reported elsewhere [2,5,7-12], although diarrhea was present in only $11 \%$ of patients compared to rates of $20-73 \%$ reported in studies from Hong Kong and Canada [7-9]. Like other SARS outbreaks, many cases (41.3\%) were acquired after exposure in the hospital environment, with healthcare workers providing $34 \%$ of cases at this institution. Of note was a case of SARS possibly acquired in a diagnostic laboratory. There have since been a number of cases acquired in research laboratories [1].

Detection of SARS-CoV RNA by RT-PCR is only moderately useful in the early diagnosis of SARS, as the maximal viral load and RT-PCR sensitivity occurs in the second week of illness [9]. In addition, the sensitivity of SARSCoV RT-PCR on specimens collected from different sites and at different time points in the illness varies. Testing more than one clinical specimen increases the likelihood of obtaining a positive RT-PCR result. In one large study, $60 \%$ of patients with clinical SARS had a positive SARSCoV RT-PCR in one or more clinical specimens, with the highest detection rates in sputum (55.6\%), NPAs (29.6\%) and nose/throat swabs $(20 \%)$ collected within the first 5 days of illness [10]. We found that the likelihood of a positive SARS-CoV RT-PCR was similar in serum (54.3\%) and throat washes $(56.6 \%)$ in the first 9 days of illness. We found the peak of SARS-CoV detection in throat washes to be between days 5 to 14 , where $60.8 \%$ (42/69) of samples were positive, similar to reported rates in other respiratory specimens $[9,10]$. The viral loads in throat washes decreased over time and were at levels between those in feces and sera at similar time points.

In other studies, throat swabs were RT-PCR positive in $37.5 \%$ of probable SARS cases, reaching $50-60 \%$ on days $7-10$, and consistent with earlier studies showing peaks of virus shedding in the respiratory tract in the second week of illness [9,11]. High viral loads were seen in NPAs in 14 patients with SARS, mainly in the second week of illness [9]. The use of patient self-collected throat washings may reduce risks to healthcare workers, although lower respiratory tract samples such as sputum, NPAs or bronchoalveolar lavage fluid are likely to have higher viral loads and 
Table I: Detection and quantitation of SARS-CoV RNA by RT-PCR in sera.

\begin{tabular}{cccc}
\hline Days after onset & Samples & Positive (number, \%) & Viral load (log ${ }_{10}$ copies/ml \pm SD) \\
\hline $1-4$ & 76 & $38(50)$ & $2.74 \pm 0.88$ \\
$5-9$ & 154 & $87(56.5)$ & $2.78 \pm 1.04$ \\
$10-14$ & 129 & $39(30.2)$ & $2.58 \pm 1.02$ \\
$15-19$ & 88 & $24(27.3)$ & $2.27 \pm 0.85$ \\
$20-24$ & 24 & $4(16.7)$ & $2.11 \pm 1.04$ \\
$\geq 25$ & 143 & $192(31.3)$ & - \\
Total & 614 & $2.65 \pm 0.99$ \\
\hline
\end{tabular}

offer increased likelihood of SARS-CoV detection by RTPCR. We were unable to correlate viral loads in the various clinical samples with ability to isolate virus or transmission to other people; whether viral load in the respiratory tract correlates with 'super-shedding' events is uncertain.

Although overall SARS-CoV detection rates and viral load in throat washes and stools were higher than in the serum, serum SARS-CoV RT-PCR is a useful investigation early in the illness as we found that $50 \%$ of sera had SARS-CoV detected in the first four days of illness. One study of sera from 8 probable SARS patients found a detectable SARSCoV load ranging from $2 \times 10^{3}$ to $1 \times 10^{4}$ copies $/ \mathrm{ml}$ serum in $50 \%$ of the samples, but not after 12 days after onset [13]. Of interest was that occasional serum samples from individuals remained SARS-CoV RT-PCR positive (with moderate viral loads) over three weeks after onset of illness, a feature noted in another study [14].

High rates of SARS-CoV RT-PCR detection (as high as $86.3 \%$ between days 10-19) and high viral loads were found in fecal samples in the second to fourth weeks of disease. Rates of SARS-CoV detection in fecal samples began to decrease after one month, although many stools were still SARS-CoV RNA positive 40 days or more after the onset of the clinical illness. The SARS-CoV load in fecal samples collected after 40 days were higher than the peak load seen in sera collected early in disease, and comparable to the viral load in throat washes in the second week of illness. Both lower $(27 \%$ in fecal samples collected 11-20 days after onset) and similar high detection rates (over $80 \%$ in stools collected $11-16$ days after onset) have been reported elsewhere, as have fecal samples posi- tive 40 days or more after onset $[10,14]$. Despite the high SARS-CoV load in feces, diarrhea was not a prominent clinical feature in this cohort. Long-term fecal viral shedding may be an additional source of community spread of SARS, although the infectivity of feces may be better assessed with virus isolation.

Direct comparisons of the sensitivity and specificity of RTPCR for the detection of SARS-CoV are hampered by the use of different types of clinical specimens, RNA extraction procedures and different RT-PCR techniques. The first published interlaboratory comparison showed sensitivities of $61 \%$ and $68 \%$ for 72 NPAs, $65 \%$ and $72 \%$ for 54 throat swabs, $50 \%$ and $54 \%$ for 78 urine samples and $58 \%$ and $63 \%$ for 19 stool specimens, with an overall specificity of $100 \%$ [15]. To date, no significant differences in the sensitivity and specificity of various commercial and in-house RT-PCR or other molecular assays have been reported [16-18].

\section{Conclusion}

SARS-CoV infection results in a severe respiratory disease. It causes significant nosocomial infection and requires aggressive infection control practices rarely used for other causes of atypical pneumonia. Laboratory confirmation of SARS is crucial in the management of patients presenting with pneumonia, particularly as the clinical features of SARS make it difficult to distinguish from other causes of atypical pneumonia. Molecular methods for SARS diagnosis are useful, although their value is affected by the observation that maximal viral shedding occurs after the first week of illness rather than at the initial clinical presentation. The SARS outbreak was characterized by high

Table 2: Detection and quantitation of SARS-CoV RNA by RT-PCR in throat washes.

\begin{tabular}{cccc}
\hline Days after onset & Samples & Positive (number, \%) & Viral load (log ${ }_{10}$ copies/ml \pm SD) \\
\hline $1-4$ & 8 & $3(37.5)$ & $4.73 \pm 0.45$ \\
$5-9$ & 45 & $27(60)$ & $3.59 \pm 1.36$ \\
$10-14$ & 24 & $15(62.5)$ & $3.33 \pm 1.37$ \\
$15-19$ & 11 & $5(45.5)$ & $1.88 \pm 1.00$ \\
$20-24$ & 4 & 0 & - \\
$\geq 25$ & 4 & 0 & - \\
Total & 96 & $50(52.1)$ & $3.45 \pm 1.39$ \\
\hline
\end{tabular}


Table 3: Detection and quantitation of SARS-CoV RNA by RT-PCR in fecal samples.

\begin{tabular}{cccc}
\hline Days after onset & Samples & Positive (number, \%) & Viral load (log copies $/ g \pm$ SD) \\
\hline $10-19$ & 51 & $44(86.3)$ & $6.06 \pm 2.05$ \\
$20-29$ & 54 & $38(70.4)$ & $4.51 \pm 1.23$ \\
$30-39$ & 62 & $28(45.2)$ & $3.82 \pm 1.44$ \\
$40-53$ & 57 & $17(29.8)$ & $3.57 \pm 1.25$ \\
Total & 224 & $127(56.7)$ & $4.37 \pm 1.61$ \\
\hline
\end{tabular}

infection rates in healthcare workers; patient self-collected specimens such as throat washes or feces, or serum may pose less risk to healthcare workers, particularly in the context of concerns about nosocomial acquisition. Although NPAs and other lower respiratory tract samples are the sample of choice for suspected respiratory viral infections, patient self-collected specimens are suitable for RT-PCR. Thus they offer diagnostic value, especially in SARS where the peak of viral shedding is after the first week of illness, and this sampling approach may reduce the safety issues of healthcare workers collecting NPAs. Patient self-collected specimens may be less appropriate for common seasonal respiratory virus infections such as influenza, where viral shedding is maximal at clinical presentation and virus is rarely detected outside the respiratory tract. Accurate and rapid laboratory diagnosis will become even more important as SARS becomes less common, or in the event of new outbreaks of SARS, especially if influenza or other seasonal respiratory viruses are co-circulating.

\section{Methods}

This study was conducted during the first three months (March-May 2003) of the SARS outbreak in Beijing, China, where Ditan Hospital was designated as a 'SARS hospital', meaning that suspected SARS patients were transferred and managed at this institution. The study was approved by the Ethics Committee of the Beijing Ditan Hospital. The clinical case definition of probable SARS included a fever of $\geq 38^{\circ} \mathrm{C}$, cough or shortness of breath, new pulmonary infiltrates on chest radiography, and close contact with a suspect or probable SARS case. Day 1 was defined as the day of fever onset.

Sera, throat washes and feces were collected from hospitalised patients for testing with a quantitative SARS-CoV RT-PCR. As the early phase of the outbreak in Beijing had involved many healthcare workers [2], patient self-collected throat washes and fecal samples were used to minimize further nosocomial transmission. For throat washes, patients were given $10 \mathrm{ml}$ of sterile $0.9 \% \mathrm{NaCl}$, asked to gargle for 30 seconds then spit the fluid into a 20 $\mathrm{ml}$ sterile plastic screw-topped plastic container. Patients were also asked to collect approximately $1 \mathrm{~cm}^{3}$ feces and place it into a $20 \mathrm{ml}$ sterile screw-topped plastic container.
Five $\mathrm{ml}$ of the throat wash was centrifuged at $10,000 \mathrm{~g}$ for 10 minutes, then the supernatant further centrifuged at $20,000 \mathrm{~g}$ for 1 hour. Ten $\mathrm{ml}$ of $0.01 \mathrm{M}$ phosphate buffered saline ( $\mathrm{pH} 7.2$ ) was used to dilute the fecal sample, then $5 \mathrm{ml}$ was centrifuged at $10,000 \mathrm{~g}$ for 10 minutes. The supernatant was further centrifuged at $20,000 \mathrm{~g}$ for 1 hour. RNA was extracted from the remaining 100-300 $\mu \mathrm{l}$ of the throat wash and fecal pellets using Trizol (Invitrogen, Beijing, PR China). $700 \mu$ l of sera were centrifuged at $20,000 \mathrm{~g}$ for 1 hour, the supernatant removed and RNA extracted from the remaining $100-300 \mu$ l pellet using Trizol.

SARS-CoV RNA was detected in throat washes, stool and blood using a fluorescence quantitative RT-PCR assay (ShenZhen PJ Biotech Company, Shenzhen, Guangdong Province, PR China), according to the manufacturer's instructions and performed on a BioRad iCycler thermal cycler (Bio-Rad Laboratories, Beijing, PR China). The SARS-CoV pol region primers used were $P 1$ sense 5'GTTCTTGCTCGCAAACATAACACTT3' (position 15279-15303 in SARS-CoV Urbani strain, Genbank accession number AY278741), P2 antisense 5'AACAGCTTGACAAATGTTAAAGACA3' (15446-15470) and probe 5'TGTGTGGCGGCTCACTATAT3' (1537315392). Internal controls were used in all runs, and no evidence of PCR inhibition in clinical samples was detected. Testing for other respiratory viruses was not carried out in this cohort of patients as they fitted the SARS clinical case definition during the outbreak. The PCR assay was negative when performed on RNA or DNA extracted from influenza A and B, rhinovirus, respiratory syncytial virus and adenovirus isolates, and on plasma collected from otherwise healthy hepatitis C and B infected individuals (data not shown).

Manipulations were carried out in a BSL2 facility with BSL3 practices. SARS-CoV isolation was not attempted on clinical samples during the outbreak due to safety concerns and time constraints.

\section{Competing interests}

The author(s) declare that they have no competing interests. The study was funded by the Beijing Ditan Hospital. 


\section{Authors' contributions}

$\mathrm{ZH}$ and DD reviewed the data and wrote the manuscript. $\mathrm{ZH}, \mathrm{QD}, \mathrm{CZ}, \mathrm{GP}$, and HZ collected the samples and clinical data, and undetook the performance of the molecular assays. DD was a short-term consultant with the World Health Organisation in Beijing, China during the SARS outbreak in 2003.

\section{References}

I. Organization $\mathrm{WH}$ : Cumulative number of reported probable cases of severe acute respiratory syndrome (SARS). [http:// www.who.int/csr/sars/country/2004 04 21/en].

2. Liang W, Zhu Z, Guo J, Liu X, He X, Zhou W, Chin DP, Schuchat A, for the Beijing Joint SARS Expert Group: Severe acute respiratory syndrome, Beijing, 2003. Emerging Infectious Diseases 2004, 2004:25-31.

3. Ksiazek TG, Erdman D, Goldsmith CS, Zaki SR, Peret T, Emery S, Tong S, Urbani C, Corner JA, Lim W, Rollin PE, Nghiem KH, Dowell $S$, Ling AE, Humphrey C, Shieh WJ, Guarner J, Paddock CD, Rota $P$ Fields B, DeRisi J, Yang JY, Cox N, Hughes J, LeDuc JW, Bellini WJ, Anderson LI, Group SARSW: A novel coronavirus associated with severe acute respiratory syndrome. New England Journal of Medicine 2003, 348:1953-1966.

4. Drosten C, Gunther S, Preiser W, van der Werf S, Brodt HR, Becker S, Rabenau H, Panning M, Kolesnikova L, Fouchier RAM, Berger A, Burguiere AM, Cinatl j, Eickmann M, Escriou N, Grywna K, Kramme S, Manuguerra JC, Muller S, Rickerts V, Sturmer M, Vieth S, Klenk HD, Osterhaus ADME, Schmitz H, Doerr HW: Identification of a novel virus in patients with severe acute respiratory syndrome. New England Journal of Medicine 2003, 348: 1967-1976.

5. Peiris JSM, Lai ST, Poon LLM, Guan Y, Yam YC, Lim W, Nicholls J, Yee WKS, Yan WW, Cheung MT, Cheng VCC, Chan KH, Tsang NC, Yung RWH, Ng TK, Yuen KY, and members of the SARS Study Group: Coronavirus as a possible cause of severe acute respiratory syndrome. Lancet 2003, 36 I: |3 | $9-1325$.

6. He Z, Dong Q, Zhuang H, Song S, Peng G, Guangxiang L, Dwyer DE: Kinetics of severe acute respiratory syndrome (SARS) coronavirus-specific antibodies in 27 I laboratory confirmed cases of SARS. Clinical and Diagnostic Laboratory Immunology 2004, I I:792-794.

7. Booth CM, Matukas LM, Tomlinson GA, Rachlis AR, Rose DB, Dwosh HA, Walmsley SL, Mazzulli T, Avendano M, Derkach P, Ephtimios IE, Kitai I, Mederski BD, Shadowitz SB, Gold WL, Hawryluck LA, Rea E, Chenkin JS, Cescon DW, Poutanen SM, Detsky AS: Clinical features and short-term outcomes of I 44 patients with SARS in the Greater Toronto Area. Journal of the American Medical Association 2003, 289: I-9.

8. Lee N, Hui D, Wu A, Chan P, Cameron P, Joynt GM, Ahuja A, Yung MY, Leung CB, To KF, Lui SF, Szeto CC, Chung S, Sung JJY: A major outbreak of severe acute respiratory syndrome in Hong Kong. New England Journal of Medicine 2003, 348:1986- 1994.

9. Peiris JSM, Chu CM, Cheng VCC, Chan KS, Hung IFN, Poon LLM, Law $\mathrm{KI}$, Tang BSF, Hon TYW, Chan CS, Chan KH, Ng JSC, Zheng BJ, Ng WL, Lai RWM, Guan Y, Yuen KY, and members of the HKU/UCH SARS Study Group: Clinical progression and viral load in a community outbreak of coronavirus-associated SARS pneumonia: a prospective study. Lancet 2003, 361: 1767-1772.

10. Chan KH, Poon LLLM, Cheng VCC, Guan Y, Hung IFN, Kong J, Yam LYC, Seto WH, Yuen KY, Peiris JSM: Detection of SARS coronavirus in patients with suspected SARS. Emerging Infectious Diseases 2004, 10:294-299.

11. Wu HS, Chiu SC, Tseng TC, Lin SF, Lin JH, Hsu YF, Wang MC, Lin TL, Yang WZ, Ferng TL, Huang KH, Hsu LC, Lee LL, Yang JY, Chen HY, Su SP, Yang SY, Lin TH, Su IJ: Serologic and molecular biologic methods for SARS-associated coronavirus infection, Taiwan. Emerging Infectious Diseases 2004, 10:304-310.

12. Lang ZW, Zhang LJ, Zhang SJ, Meng X, Li JQ, Song CZ, Sun L, Zhou YS, Dwyer DE: A clinicopathological study of three cases of severe acute respiratory syndrome (SARS). Pathology 2003, 35:526-531.

13. Ng LFP, Wong M, Koh S, Ooi EE, Tang KF, Leong HC, Ling AE, Agathe LV, Tan J, Liu ET, Ren EC, Ng LC, Hibberd ML: Detection of severe acute respiratory syndrome coronavirus in blood of infected patients. Journal of Clinical Microbiology 2004, 42:347-350.

14. Zhai J, Briese T, Dai E, Wang X, Pang X, Du Z, Liu H, Wang J, Wang H, Guo Z, Chen Z, Jiang L, Zhou D, Han Y, Jabado O, Palcios G, Lipkin WI, Yang R: Real-time polymerase chain reaction for detecting SARS coronavirus, Beijing, 2003. Emerging Infectious Diseases 2004, 10:300-303.

15. Yam WC, Chan KH, Poon LLM, Guan Y, Seto WH, Peiris JSM: Evaluation of reverse transcription-PCR assays for rapid diagnosis of severe acute respiratory syndrome associated with a novel coronavirus. Journal of Clinical Microbiology 2003, 4I:452I-4524.

16. Mahony JB, Petrich A, Louie L, Song X, Chong S, Smieja M, Chernesky M, Loeb M, Richardson S: Ontario Laboratory Working Group for the Rapid Diagnosis of Emerging Infections: Performance and cost evaluation of one commercial and six in-house conventional and real-time reverse transcription-PCR assays for detection of severe acute respiratory syndrome coronavirus. Journal of Clinical Microbiology 2004, 42:452 I-4524.

17. Wang B, Potter SJ, Lin Y, Cunningham AL, Dwyer DE, Su Y, Hou Y, Saksena NK: Rapid and sensitive detection of Severe Acute Respiratory Syndrome coronavirus by rolling circle amplification. Journal of Clinical Microbiology 2005, 43:2339-2344.

18. Yam WC, Chan KH, Chow KH, Poon LLM, Lam HY, Yuen KY, Seto WH, Peiris JSM: Clinical evaluation of real-time PCR assays for rapid diagnosis of SARS coronavirus during outbreak and post-epidemic periods. Journal of Clinical Virology 2005, 33:19-24.
Publish with BioMed Central and every scientist can read your work free of charge

"BioMed Central will be the most significant development for disseminating the results of biomedical research in our lifetime. "

Sir Paul Nurse, Cancer Research UK

Your research papers will be:

- available free of charge to the entire biomedical community

- peer reviewed and published immediately upon acceptance

- cited in PubMed and archived on PubMed Central

- yours - you keep the copyright 